Article

\title{
Assessing the Weed-Suppressing Potential of Cotton Chromo- some Substitution Lines Using the Stair-Step Assay
}

\author{
Mary Gracen Fuller ${ }^{1}$, Sukumar Saha ${ }^{2}$, David M. Stelly ${ }^{3}$, Johnie N. Jenkins ${ }^{4}$, Te-Ming Tseng ${ }^{5 *}$ \\ ${ }^{1}$ Department of Plant and Soil Science,, Mississippi State University, Mississippi State, MS 39762; \\ maf572@msstate.edu. \\ 2 USDA-ARS, Crop Science Research Lab, Genetics and Sustainable Agriculture Research Unit, Mississippi \\ State, MS 39762; sukumar.saha@usda.gov, ORCID ID 0000-0002-13 3586-8411. \\ 3Department of Soil and Crop Sciences, Texas A\&M University, College Station, Texas 77843; stelly@tamu.edu, \\ ORCID ID 0000-0002-3468-4119. \\ ${ }^{4}$ USDA-ARS, Crop Science Research Lab, Genetics and Sustainable Agriculture Research Unit, johnie.jen- \\ kins@usda.gov, ORCID ID 0000-0002-3586-8411. \\ ${ }^{5}$ Department of Plant and Soil Science, Mississippi State University, Mississippi State, MS 39762; \\ t.tseng@msstate.edu, ORCID ID 0000-0002-8102-8149. \\ * Correspondence: t.tseng@msstate.edu; Tel.: +1 662-325-4725
}

\begin{abstract}
Palmer amaranth (Amaranthus palmeri) is a problematic common weed species, especially in cotton (Gossypium hirsutum). With the wide use of chemical herbicide and herbicide-tolerant transgenic cotton lines, Palmer amaranth populations have developed tolerance to commonly used herbicides. It is imperative to develop alternative weed control methods to slow the evolution of herbicide-resistant weed populations and provide new sources for weed management. Eleven chromosome substitution (CS) cotton lines CS-B26lo, CS-T17, CS-B16-15, CS-B17-11, CS-B12, CS-T05sh, CS-T26lo, CS-T11sh, CS-M11sh, CS-B22sh, and CS-B22lo were screened for weed-suppressing abilities in this study. The cotton lines were tested using the established stair-step structure methodology, which provided scope to study the effect of individual CS lines on the growth and development of Palmer amaranth weed without any interference of other external factors in the greenhouse. Height $(\mathrm{cm})$ and chlorophyll concentration (cci) were measured for each plant in the system. The data were analyzed as a randomized complete block design using LSD mean comparisons of the genotypes at the $\mathrm{P} \leq .05$ level. The $14^{\text {th }}$ day after establishment resulted in the most significant variation in Palmer amaranth height reduction among the CS lines. Results indicated that CS-B22sh had the highest effect in reducing Palmer amaranth height and chlorophyll concentration with the most heightened susceptibility for Palmer amaranth. The cluster analysis revealed that Enlist ${ }^{\circledR}$ cotton, CS-CS-B22sh, and CS-T26lo were clustered in one group suggesting similar genetic potential with reference to Palmer amaranth growth and development. CS-B22sh showed novel genetic potential to control the growth and development of Palmer amaranth, a major weed in cotton fields. In the future, it will be interesting to investigate if CS-B22sh exudates from its root contain allelochemicals able to impede the growth and development of Palmer amaranth.
\end{abstract}

Keywords: Allelopathy; Gossypium hirsutum; chromosome substitution; sustainable weed management. 


\section{Introduction}

Weed Science is a discipline focused on plants that are considered a nuisance (Zimdahl 2018). The definition of what is regarded as a weed largely depends on the human perspective and is generally considered a plant growing somewhere it is not desired (Buchholtz 1967; Humburg \& Colby 1989). Today, one of the most troublesome weeds facing farmers and weed scientists is Palmer amaranth (Amaranthus palmeri), a broadleaved, herbaceous dicot capable of prolific seed production and aggressive early seasonal growth (Culpepper et al. 2010; Morgan, Baumann \& Chandler 2001). Competition imposed by weeds affects the crop directly and indirectly by (a) reducing fiber quality, (b) reducing crop yield, (c) increasing production costs, (d) reducing irrigation efficiency, and (e) serving as hosts and habitats for pests such as insects, rodents, nematodes, and diseasecausing pathogens. Palmer amaranth negatively affects many economically important crops, including soybean, sorghum, and cotton (Morgan, Baumann \& Chandler 2001). Furthermore, Palmer amaranth is considered the most problematic weed species in eight cotton-producing states, including Mississippi (Webster \& Nichols 2012; Braxton et al. 2017), and has been observed to reduce cotton lint up to $54 \%$ (Morgan, Bumann \& Chandler 2001; MacRate et al. 2013). Palmer amaranth also decreases harvesting proficiency to $2.4 \%$ when the weed is present at a density of 3,260 weeds ha- ${ }^{-1}$ (Smith, Baker, \& Stelle 2000).

Palmer amaranth and other weeds found in cotton fields have been traditionally managed through appropriate cultivation, pre-planting, and timed herbicide applications (preemergence and postemergence herbicide application) (Wilcut et al. 1995; Webster \& Nichols 2012); the last of which has become more prevalent in modern agricultural practice due to technological advancements (Appleby 2005). The compound glyphosate is a key ingredient in Bayer's Roundup Ready herbicide, a common and effective tool in managing weeds in many economically important agricultural fields such as cotton and soybean (Webster \& Sosnoskie 2010). First introduced to the market in 1974, the herbicide effectively interrupts the Shikimate Pathway by downregulating the 5-enolpyruvylshikimate-3-phosphate synthase (EPSPS) enzyme. This pathway is crucial for plants to produce aromatic amino acids such as tyrosine and phenylalanine and, when interrupted, results in plant death (Xu et al. 2019).

Glyphosate revolutionized agricultural weed management due to the initial belief that the herbicide was not toxic in mammals and relatively inactive in soil (Humburg \& Colby 1989). The use of glyphosate has exponentially increased in conjunction with the development and introduction of glyphosate-resistant (GR) crops in the 1990s, including cotton, soybean, and rice (Xu et al. 2019; Zimdahl 2018). It has been found that glyphosate has adverse side effects not previously considered. For example, many herbicides using glyphosate often mixed phytotoxic chemicals with additives such as surfactants, which directly impact the effectiveness of the herbicide mixture (Székács \& Darvas 2018). Research conducted by Mesnage, Bernay, and Séralini (2013) suggested that phytotoxic chemicals mixed with adjuvants are 10,000 times more toxic to mammalian mitochondrial activity than phytotoxic chemicals alone (Mesnage, Bernay \& Séralini 2013).

Furthermore, in many agricultural systems, glyphosate is used exclusively for weed control (Webster \& Nichols 2012). The overuse of and reliance on glyphosate and other herbicides without rotation in many agricultural systems (Webster \& Nichols 2012; VanGEssel 2001; Comont et al. 2019; Humburg \& Colby 1989) has led to the development of herbicide resistance in over 200 weedy species all over the world, including the problematic Palmer amaranth (Amaranthus palmeri) (Trangel, Wright \& Heap 2019). Glyphosate-resistant Palmer amaranth has primarily been managed using glufosinate, dicamba, and 2,4-D herbicides (Norwsworth et al. 2008), in conjunction with 2,4-D and dicambaresistant cotton varieties (Norsworthy et al. 2012). Due to the rapid evolution of resistant Palmer amaranth, it is reasonable to assume that Palmer amaranth populations will become resistant to glufosinate, dicamba, and 2,4-D herbicides, as was elucidated with glyphosate (Norsworthy et al. 2012). To curb the evolution of herbicide-resistant (HR) 
weed populations, alternative weed control techniques must be developed to supplement chemical weed management in agriculture (Charles, Taylor \& Roberts 2004).

Numerous studies on rice, wheat, sunflower, and canola crop varieties have illustrated the capability of some plants to possess weed-suppressing abilities, also known as allelopathy (Kong et al. 2011; Sun et al. 2012). Allelopathy is an observed phenomenon in which secondary metabolites from plants, produced by biochemical pathways, inhibit the growth of neighboring plants, thereby reducing competition and increasing the plant of interest's success, growth, and fecundity (Rizvi 2012; Kong et al. 2011). This phenomenon can be utilized in conjunction with chemical control techniques to effectively suppress weed competition in agricultural fields and take the pressure off chemical control management techniques. Allelopathic crop varieties are up-and-coming for the modern frontier of agriculture because the chemicals produced by the plant of interest are generally biodegradable and safer than conventional herbicides (Rizvi 2012). Although no research has been conducted on the allelopathic effect of cotton on weed species, studies have indicated the ability of cotton varieties to produce allelochemicals. In 1996, Hoffman et al. studied cotton that was observed to inhibit the growth of weeds, including Palmer amaranth (Gui-Ying et al. 2015; Hoffman et al. 1996). Additionally, research conducted by GuiYing et al. (2015) detected four phenolic acid compounds in extracts of cotton roots from fields that had been monocropped for an extended period (>10 years); these phenolic acids were classified as p-hydroxybenzoic acid, ferulic acid, gallic acid, and vanillin (Gui-Ying et al. 2015). Phenolic compounds such as sorgoleone from sorghum have been demonstrated to reduce barnyardgrass and velvetleaf growth up to 50\% (Hoffman et al. 1996). Total phenolic acid from sunflower (at $600 \mu \mathrm{g} / \mathrm{g}$ soil) resulted in up to $68 \%$ inhibition of redroot pigweed germination (Hall et al. 1982). Due to the suppression of weed growth when in the presence of phenolic allelochemicals produced by crops of interest, it is reasonable to assume that cotton varieties capable of producing phenolic compounds may possess weed-suppressive potential. To cultivate this characteristic in cotton plants, it is imperative to identify cotton lines that can produce high levels of allelochemicals. They can then be entered into selective breeding programs to develop cotton varieties with substantial weed suppressive ability. Weed suppressing cotton varieties can contribute to sustainable cotton production and restrain the evolution of HR weeds.

The cotton genome, while large $(2 n=52)$ (Saha et al. 2006), is mainly composed of homogenous gene segments (Chen et al. 2007). The long-term domestication and refinement of Gossypium hirsutum cultivars are suspected to be the reason for the species' marked decline in intraspecific polymorphism (Wendel et al. 1992). This lack of genetic variability has left little for growers, agronomists, and geneticists to work with when faced with novel problems, such as HR weed populations. Developed in 2006 by Saha et al., chromosome substitution (CS) cotton lines are characterized by the interspecific introgression of alleles from alternative cotton species (Saha et al. 2006). Initially engineered to improve fiber quality in Upland cotton (Gossypium hirsutum), the CS lines were created by substituting a portion of the chromosome with the mirroring chromosome portion present in wild or exotic species of cotton (Gossypium barbadense, G. mustillenum, G. darwinii, G. tomentosum). Each CS line contains about $4 \%$ of the alternative species' genome, with the remaining portion being isogenic to the TM-1 parent (Saha et al. 2011). The lines have been observed to maintain epistatic genetic effects, altering the expression of traits in unprecedented ways (Wu et al. 2008).

In preliminary greenhouse experiments (unpublished), the 50 CS lines were screened for their competitive ability. The competitive lines were determined to be: CS-B26lo, CST17, CS-B16-15, CS-B17-11, CS-B12, CS-T05sh, CS-T26lo, CS-T11sh, CS-M11sh, CS-B22sh, and CS-B22lo. These lines were further phenotyped in this study. The main objective of the project was to phenotype competitive CS lines in a greenhouse using the stair-step structure to observe potential weed-suppressing characteristics.

\section{Results}


Weed suppressive or otherwise competitive chromosome substitution (CS) cotton lines were determined using the reduction in mean height reduction and chlorophyll concentration of Palmer amaranth, the receiver plant species. The entire system was run for a total of 21 days after establishment. Height reduction was observed to be statistically different 14 DAE. For this reason, height reduction values were measured starting at 14 DAE. Palmer amaranth leaves were too small to measure chlorophyll concentration without irreparable damage to the plant at 1, 7, and 14 DAE. For this reason, chlorophyll concentration was measured at 21 DAE.

\subsection{Height Reduction}

Height reduction values for both runs were pooled and analyzed at each day of data collection (DOE, 7, 14, and 21 DAE) using ANOVA, where $\mathrm{p}<0.05$ (Table 1). There were no significant differences in Palmer amaranth height reduction 7 or 14 DAE. On 21 DAE, significant differences in Palmer amaranth height reduction among the CS lines, UA48, Enlist ${ }^{\circledR}$, and TM1 were observed (Figure 3). A p-value of 0.0336 was calculated. The topperforming line was determined to be CS-B22sh, which reduced Palmer amaranth height by nearly $77 \%$. This line reduced Palmer amaranth height approximately $69 \%$ more than the lowest-performing line, CS-T05sh, with an overall Palmer amaranth height reduction value of $24.06 \%$. Additionally, CS-B22sh reduced Palmer amaranth height reduction nearly $30.1 \%$ more than Enlist ${ }^{\circledR}(\sim 53 \%$ Palmer amaranth height reduction), approximately $60 \%$ more than TM1 ( $\sim 31 \%$ Palmer amaranth height reduction), and $\sim 63 \%$ more than UA48 ( $\sim 28 \%$ Palmer amaranth height reduction). The CS line CS-T26lo also performed exceptionally well in terms of Palmer amaranth height reduction with a mean value of more than $68 \%$.

\subsection{Chlorophyll Reduction}

Chlorophyll reduction values for both runs at 21 DAE were pooled and analyzed using ANOVA. Analysis indicated no significant differences among CS lines, UA48, TM1, and Enlist ${ }^{\circledR}$. Conversely, Palmer amaranth chlorophyll reduction was 38 and $55 \%$ greater than UA48 and TM1, respectively.

\subsection{Cotton Reduction}

On 14 DAE, analyses of variance revealed significant differences among CS line height reduction due to weedy interactions. Comparison of means revealed CS-B22lo height was reduced more by Palmer amaranth than all other CS lines, where $\mathrm{p}=0.0358$. Furthermore, on $21 \mathrm{DAE}, \mathrm{CS}-\mathrm{B} 22 \mathrm{lo}$ suffered increased height reduction compared to the lowest-performing CS lines with a probability value of 0.0304 . There was no significant data for cotton height reduction on the day of establishment. Furthermore, there were no significant differences in cotton chlorophyll reduction between the CS line, UA48, Enlist ${ }^{\circledR}$, and TM1 (Table 2).

\subsection{Hierarchical Clustering and Principal Component Analysis}

Clustering analyses were performed utilizing the following five parameters (Table 1): Palmer amaranth mean height reduction 7 DAE (\%), Palmer amaranth mean height reduction 14 DAE (\%), Palmer amaranth mean height reduction 21 DAE (\%), and Palmer amaranth chlorophyll concentration reduction $21 \mathrm{DAE}(\%)$. The parameters were pooled and analyzed using a hierarchical cluster guided by K-clustering analysis. Three separate groups emerged. Principal Component Analysis (PCA) guided by hierarchical clustering indicates that $63.8 \%$ of the weed-suppressing characteristics variation can be attributed to component 1 , and $20.3 \%$ can be attributed to component 2 (Figure 4). The first group is composed of lines: CS-B22lo, CS-B12, CS-B10, CS-T11sh, and UA48. This group maintained median Palmer amaranth chlorophyll reduction values ranging from approximately $21 \%$ to $16.5 \%$. The second group was composed of CS-T05SH, CS-B26lo, CS-B1615, CS-B17-11, CS-M11sh, CS-T17, and TM1. This group did not have high reduction values for Palmer amaranth chlorophyll concentration or height reduction of any days of 
data collection. The third group was composed of CS-T26lo, CS-B22sh, and Enlist®. This group represents cotton accessions with high Palmer amaranth height reduction values.

\section{Discussion}

Herbicide technology utilized to manage crops and weedy populations act to influence and shape the emergence of ecotypes in the future (Webster \& Nichols 2012); consequently, reliance on a small variety of herbicides with little to no rotation has resulted in the emergence of weedy biotypes that have developed resistance to one or more herbicides used in agricultural practice today (Webster \& Nichols 2012; VanGessel 2001). A current weed science challenge is developing new biotechnologies and crops that can combat herbicide-resistant weed populations while maintaining low mammalian toxicity and low residual time in soil. Competitive or allelopathic cotton varieties have the potential to serve as a powerful tool for farmers. The cotton CS lines were tested using the established stair-step structure methodology, which provided scope to study the effect of individual CS lines on the growth and development of Palmer amaranth weed without any interference of other external factors in the greenhouse.

Results indicated that CS-B22sh showed the highest effect in reducing Palmer amaranth height and chlorophyll concentration as well as with the most heightened susceptibility for Palmer amaranth (Table 1). The height of CS-B22sh was the least affected, suggesting that Palmer amaranth did not adversely affect the height of CS-B22sh (Table 2). Results indicated that Palmer amaranth had no affect on the growth and development of the CS lines. The cluster analysis revealed that Enlist ${ }^{\circledR}$ cotton, CS-CS-B22sh, and CS-T26lo were clustered in one group suggesting similar genetic potential in reducing the growth and development of Palmer amaranth (Figure 1). The discovery of cotton lines with the genetic potential to impede weed growth and development will provide economic benefit to the farmers.

Stelly et al. (2005) successfully created and released 17 cotton CS lines by crossing the genetic standard for Upland Cotton (Gossypium hirsutum), TM-1, with the genetic standard for Pima Cotton (Gossypium barbadense), 3-79. Through the utilization of hypoaneuploidybased backcross chromosome substitution method, telosomic TM-1 chromosome paired with the homologous chromosome arm of 3-79 and created the CS line ultimately through a three-step procedures, including (1) development of a hypoaneuploid stock, (2) introgression of G. barbadense chromosome to develop a monosomic stock, and (3) restoration of disomy through interbreeding (Stelly et al. 2005). Follow-up work using a similar method resulted in the development of CS-T lines by following the same protocol with Hawaiian Cotton (Gossypium tomentosum) instead of Pima Cotton (Gossypium barbadense) (Saha, Raska \& Stelly 2006).

Resources for growth and reproduction are not infinite within a plant. In concordance with plant resource allocation theory, as a plant dedicates more energy and resources to reproduction, fewer resources will be devoted to growth (Weiner 2004). In addition to growth and reproduction, defense is a plant's mechanism that requires resources. Chromosome substitution (CS) lines exhibiting more competitive or allelopathic characteristics may dedicate more resources to defense mechanisms than growth. In studies conducted by Wu et al. (2009), it was observed that CS line B16 (CS-56) was consistently shorter than TM-1 cotton plants at all stages of growth, indicating that chromosome 16 in G. barbadense is associated possibly with additive effects resulting in reduced plant height (Wu et al. 2009). This could be why alleles derived from chromosome 16 in G. barbadense resulted in more competitive behavior in this study but are also associated with stunted plant height (Wu et al. 2009). Genetic analyses conducted by $\mathrm{Hu}$ et al. (2019) revealed that G. hirsutum is more tolerant to heat and cold stressors than G. barbadense ( $\mathrm{Hu}$ et al. 2019). Allelopathy is often a response to stressful environments (Kruse et al. 2000). This study indicates CS-B22sh and CS-T26lo were among the top two lines, even compared to the herbicide tolerant transgenic cotton Enlist ${ }^{\circledR}$, in terms of Palmer amaranth height and chlorophyll concentration reduction. It could be implied that genes associated with these CS 
lines are more sensitive to competition with weeds and likely produces potential allelochemicals to inhibit weed growth and development.

G. tomentosum, or Hawaiian cotton, is in the primary gene pool of Gossypium species and closely related to Upland cotton (G. hirsutum); however. However, G. tomentosum exhibits marked differences in terms of markers, isozymes, and phenotype. Gosspyium tomentosum was reported by Brubaker et al. (1999) to produce thin, coarse fiber that is generally brown and strong (Brubaker, Bourland \& Wendel 1999). Furthermore, Gossypium tomentosum has been especially heat-resistant, likely because this species evolved in the Hawaiian Islands, characterized by dry, rocky coastal habitats (Saha, Raska \& Stelly 2006). Our results indicated that CS-T26lo is one of the two top-performing lines for reducing height and chlorophyll concentration of Palmer amaranth. G. tomentosum possibly developed the cryptic alleles for weed suppressing ability in evolution to compete with other plant species under minimum availability of water and nutrition in wild habitats. However, during the domestication process, due to the intense selection pressure on fiber traits, some of these wild beneficial traits have been lost in Upland cotton, suggesting CS lines will be a handy tool for targeted introgression of many beneficial traits from wild species in Upland cotton improvement.

Allelopathy is closely linked to stressors within the environment (Kruse et al. 2000). For this reason, it is believed that allelopathic test results are highly dependent on the conditions in which the plants are tested. The stair-step method in our experiment provided an ideal opportunity to detect the effects of individual CS lines on the growth and development of Palmer amaranth in a controlled greenhouse condition without any interference from other external factors. Additionally, the stair-step structure outlined by Schumaker et al. (2020) calls for the use of sand to grow the plant in a pot to avoid negligible cation exchange capacity effects from other chemicals for change in phenotype on the plants in experiments (Schumaker et al. 2016; Camberato 2007). While a negligible cation exchange capacity is a useful soil characteristic when assessing the potential of allelopathic chemicals leaching from the potted plants through the connected tube to affect the effect, it is not conducive for proper cotton nutrient regiments. Additionally, cotton is a sensitive plant and displays nutrient deficiency symptoms on soils sufficient for other crops (Bednarz, Oosterhuis \& Evans 1998). We avoided this nutrient deficiency for the plants in the stair-step system by providing Hogland solution at certain time intervals to all pots to prevent nutrient deficiency in plants. Any observed greenhouse phenomenon may be altered in a field setting due to many external factors in field experiments justified by our stair-step method to study the effect of the CS lines on Palmer amaranth growth and development.

Allelopathy is considered as the release of secondary metabolites from a donor plant that affects the growth of a second receiving plant (Rizvi 2012; Kong et al. 2011); some allelopathic crops can negatively impact individuals of the same species. This autotoxicity has been observed in several species, including clovers (Trifolium ssp.) and alfalfa (Medicago sativa) (Hu et al. 2019). It is understood that the release of allelopathic exudates through root structures is likely related to biotic stress, such as defoliation. Rye was observed to proliferate the concentration of hydroxamic, a well-documented allelochemical, from shoots to roots when under biotic stress. This is hypothesized to be a survival strategy to reduce competition in the surrounding area for the plant to regenerate more easily (Kruse et al. 2000).

\section{Materials and Methods}

This project utilized eleven chromosome substitution (CS) lines that had been created using homologous chromosomes or chromosome arm of Gossypium baebadense (CS-B), Gossypium tomentosum (CS-T), and Gossypium mustellinum (CS-M), substituted for homologous pairs of Gossypium hirsutum (TM-1) chromosome or chromosome arm. The eleven CS lines utilized for this study were: CS-B26lo, CS-T17, CS-B16-15, CS-B17-11, CS-B12, CST05sh, CS-T26lo, CS-T11sh, CS-M11sh, CS-B22sh, and CS-B22lo. The parent line TM-1 and two commonly grown cotton (Enlist ${ }^{\circledR}$ and UA48) were also included. The eleven CS 
lines, TM1, Enlist ${ }^{\circledR}$, and UA48, are considered donor species were screened for their weed suppressive abilities pertaining to Palmer amaranth (Amaranthus palmeri), which is regarded as the recipient species. All plants in the study (CS lines, control varieties, Palmer amaranth) were germinated in a growth chamber using rockwool. The growth chamber was set at $53 \%$ humidity, with a day-night cycle of $16 / 8$

Upon germination, the seedlings were transplanted into pots of Quickrete Play Sand (silicon dioxide). Each pot was planted with three seedlings, and each pot was considered an experimental unit (which will be interchanged with the term 'pot' throughout this paper). The seedlings were given 2-3 weeks to establish in the sand. Once established, all experimental units were placed into a stair-step structure, as outlined by Schumaker et al. (2020) (Figure 1). Experiments were conducted in 2020 and 2021 in two runs in the greenhouse at the RR Foil Plant Science Research Center, Mississippi State University. The temperature in the greenhouse was set at $28^{\circ} \mathrm{C}$ during the day and $24^{\circ} \mathrm{C}$ at night with a $16 / 8$ hours day/night cycle. The stair-step construct consists of six descending platforms to place potted plants of interest. The first platform is outfitted with bottles. The second, third, fourth, and fifth platforms hold the potted plants in the experiment. The sixth and final platform is equipped with a collection tank and a pump. The pump is set on a timer, and every 6 hours, water is pumped through plastic tubing from the collection tank on the final platform to the corresponding bottle on the first platform. The water drains from the bottle into the descending potted plants until it drains into the collection tank. This cycle continued for the duration of the experiment. Every column is outfitted with its pump, tubes, and so forth so each column can be considered a closed-loop system and independent from one another. All water used in the experiment was distilled.

There were two columns for every CS line tested: the treatment column and the control column (Figure 2). The treatment column was composed of four pots, two containing the same CS lines and two containing Palmer amaranth. The treatment column was alternated and started with a pot of CS cotton, followed by a pot of Palmer amaranth, a pot of the same CS line, and a pot of Palmer amaranth. The control column is composed of four descending pots of the same CS line. This design was repeated for every CS line tested.

The system was fertilized using Hoagland's No. 2 basal salts (Caisson Laboratories, INC. Smithfield, UT). On the day of the establishment (DOE), a starting concentration of 1,500 mL quarter strength Hoagland's solution was used to fill each tank, respectively. This was repeated 14 days after establishment (DAE). The heights of all plants were measured in centimeters at 1, 7, 14, and 21 DAE. At 21 DAE, chloroplast concentrations were measured and recorded. Palmer amaranth height reduction was calculated using the following formula:

Height reduction $(\%)=[$ height of control PA $(\mathrm{cm})-$ height of experimental PA $(\mathrm{cm}) /$ height of control PA $(\mathrm{cm})] \times 100$

Palmer amaranth chlorophyll reduction was calculated using the following formula:

Chlorophyll concentration [cc] reduction $(\%)=[\mathrm{cc}$ of control PA (unit) $-\mathrm{cc}$ of experimental PA (unit) / cc of control PA (unit)] x 100

Where the height of the control Palmer amaranth is the mean value for all Palmer amaranth plants in the four control pot. The experimental Palmer amaranth values are derived from the mean parameter value of all PA plants present in an experimental column per CS line.

The experimental units were arranged in a randomized complete design with three replications. The experiment was run two times. Accessions were determined to be the fixed effect, and replications were understood to be the random effect. Data for heigh reduction values at $14 \mathrm{DAE}$ and chlorophyll reduction at $21 \mathrm{DAE}$ were analyzed separately by employing a general linear model, and mean values were separated using Fisher's 
Protected Least Significant Difference at or below a 0.05 probability level in JMP 14 (JMP®, Version 13. SAS Institute Inc., Cary, NC, 1989-2007). Hierarchal clustering guided by K means clustering was applied to visualize correlation among and between variables and components in JMP. This technique clustered the CS lines into associations based on Amaranthus palmeri inhibition (height and chlorophyll concentration). The data was explored through principal component analysis.

\section{Conclusions}

In the future, it will be interesting to investigate if CS-B22sh exudates from its roots contain allelochemicals able to impede the growth and development of Palmer amaranth. Allelopathic Gossypium hirsutum varieties could be a valuable tool for farmers battling herbicide-resistant weeds or otherwise seeking alternative weed control techniques (Rizvi 2012); however, allelopathic crops need to be competitive in a field setting, which would be most effective when the crop is mature enough to produce a canopy. In these situations, it would be advantageous to use chemical weed control during the critical weed-free period and rely on allelopathic chemicals later in the season (Kruse et al. 2000). Future experimentation using the stair-step structure would be helpful if water samples are taken on the day of the establishment (DOE), 7, 14, and 21 days after establishment (DAE) to analyze allelochemicals potentially present in the circulating system. Furthermore, the system could be utilized to test cotton varieties against multiple weed species. Field experiments with the selected CS lines to suppress the weed growth and development will be helpful in the future to confirm the preliminary results of this research. The discovery of novel cotton germplasm with the genetic potential to impede weed growth and development will benefit the farmers because weeds compete with the crop for nutrients and water in the same farmland.

Author Contributions: Conceptualization, T.M.T. and M.G.F.; Investigation, M.G.F. and T.M.T.; Resources, T.M.T., M.G.F., S.S., and D.M.S.; Writing - Original Draft Preparation, M.G.F., T.M.T., and S.S.; Writing - Review \& Editing, M.G.F., T.M.T., S.S., D.M.S., and J.H.J.; Visualization, M.G.F., S.S., and T.M.T.; Funding Acquisition, T.M.T.

Funding: Funding for this project was provided by Cotton Incorporated and the Mississippi Agricultural and Forestry Experiment Station, and is based upon work supported by the National Institute of Food and Agriculture, U.S. Department of Agriculture, Hatch project under accession number 230100 .

Conflicts of Interest: The authors declare no conflict of interest. 


\section{References}

Appleby, A. P. (2005). A history of weed control in the United States and Canada - a sequel. Weed Science, 53(6), 762-768.

Bednarz, C. W., Oosterhuis, D. M., \& Evans, R. D. (1998). Leaf photosynthesis and carbon isotope discrimination of cotton in response to potassium deficiency. Environmental and Experimental Botany, 39(2), 131-139.

Braxton, L. B., Richburg, J. S., York, A. C., Culpepper, A. S., Haygood, R. A., Lovelace, M. L., ... \& Walton, L. C. (2017). Resistance of Enlist ${ }^{\mathrm{TM}}(\mathrm{AAD}-12)$ Cotton to Glufosinate. Weed Technology, 31(3), 380-386.

Brubaker, C. L., Bourland, F. M., \& Wendel, J. F. (1999). The origin and domestication of cotton. Cotton: Origin, history, technology, and production. John Wiley \& Sons, New York, 3-31.

Buchholtz, K.P. (1967). Report of the terminology committee of the Weed Science Society of America. Weeds, 15, 388-389.

Camberato, J. J. (2007). Cation exchange capacity-everything you want to know and much more. Magnesium, 2(24), 240.

Charles, G., Taylor, I., \& Roberts, G. (2004). The impact of the cotton farming system on weed succession: implications for herbicide resistance and adoption of an integrated weed management approach. In 14th Australian Weeds Conference'. Wagga Wagga, NSW.(Eds BM Sindel, SB Johnson) pp (pp. 410-413).

Chen, Z. J., Scheffler, B. E., Dennis, E., Triplett, B. A., Zhang, T., Guo, W., ... \& Paterson, A. H. (2007). Toward sequencing cotton (Gossypium) genomes. Plant physiology, 145(4), 1303-1310.

Comont, D., Hicks, H., Crook, L., Hull, R., Cocciantelli, E., Hadfield, J., ... \& Neve, P. (2019). Evolutionary epidemiology predicts the emergence of glyphosate resistance in a major agricultural weed. New Phytologist, 223(3), 1584-1594.

Culpepper, A. S., Webster, T. M., Sosnoskie, L. M., York, A. C., \& Nandula, V. K. (2010). Glyphosate-resistant Palmer amaranth in the United States. Glyphosate Resistance in Crops and Weeds: History, Development, and Management. Hoboken, NJ: John Wiley E Sons, 195-212.

Gui-Ying, J., Jian-Guo, L., \& Yan-Bin, L. (2015). Allelochemicals from cotton (Gossypium hirsutum) rhizosphere soil: Inhibitory effects on cotton seedlings. Allelopathy Journal, 35(2).

Hall, A. B., Blum, U., \& Fites, R. C. (1982). Stress modification of allelopathy of Helianthus annuus L. debris on seed germination. American Journal of Botany, 69(5), 776-783.

Hoffman, M. L., Weston, L. A., Snyder, J. C., \& Regnier, E. E. (1996). Separating the effects of sorghum (Sorghum bicolor) and rye (Secale cereale) root and shoot residues on weed development. Weed Science, 402-407.

Hu, Y., Chen, J., Fang, L., Zhang, Z., Ma, W., Niu, Y., ... \& Zhang, T. (2019). Gossypium barbadense and Gossypium hirsutum genomes provide insights into the origin and evolution of allotetraploid cotton. Nature genetics, 51(4), 739-748.

Humburg, N. E., \& Colby, S. R. (1989). Herbicide handbook of the weed science society of America.

Kong, C. H., Chen, X. H., Hu, F., \& Zhang, S. Z. (2011). Breeding of commercially acceptable allelopathic rice cultivars in China. Pest management science, 67(9), 1100-1106.

Kruse, M., Strandberg, M., \& Strandberg, B. (2000). Ecological effects of allelopathic plants-a review. NERI Technical Report, 315.

MacRae, A. W., Webster, T. M., Sosnoskie, L. M., Culpepper, A. S., \& Kichler, J. M. (2013). Cotton yield loss potential in response to length of Palmer amaranth (Amaranthus palmeri) interference. J Cotton Sci, 17(3), 227-32.

Mesnage, R., Bernay, B., \& Séralini, G. E. (2013). Ethoxylated adjuvants of glyphosate-based herbicides are active principles of human cell toxicity. Toxicology, 313(2-3), 122-128.

Morgan, G. D., Baumann, P. A., \& Chandler, J. M. (2001). Competitive Impact of Palmer Amaranth (Amaranthus palmeri) on Cotton (Gossypium hirsutum) Development and Yield1. Weed Technology, 15(3), 408-412.

Norsworthy, J. K., Griffith, G. M., Scott, R. C., Smith, K. L., \& Oliver, L. R. (2008). Confirmation and control of glyphosate-resistant Palmer amaranth (Amaranthus palmeri) in Arkansas. Weed Technology, 22(1), 108-113.

Norsworthy, J. K., Ward, S. M., Shaw, D. R., Llewellyn, R. S., Nichols, R. L., Webster, T. M., ... \& Barrett, M. (2012). Reducing the risks of herbicide resistance: best management practices and recommendations. Weed science, 60(SP1), 31-62.

Pleasants, J. M., \& Wendel, J. F. (2010). Reproductive and pollination biology of the endemic Hawaiian cotton, Gossypium tomentosum (Malvaceae) 1. Pacific Science, 64(1), 45-55.

Rizvi, S. J. (Ed.). (2012). Allelopathy: basic and applied aspects. Springer Science \& Business Media.

Saha, S., Jenkins, J. N., Wu, J., McCarty, J. C., Gutiérrez, O. A., Percy, R. G., ... \& Stelly, D. M. (2006). Effects of chromosome-specific introgression in upland cotton on fiber and agronomic traits. Genetics, 172(3), 1927-1938.

Saha, S., Raska, D. A., \& Stelly, D. M. (2006). Upland Cotton (Gossypium hirsutum L.) x Hawaiian Cotton (G. tomentosum Nutt. Ex. Seem.) F1 Hybrid Hypoaneuploid Chromosome Substitution Series.

Saha, S., Stelly, D. M., Raska, D. A., Wu, J., Jenkins, J. N., McCarty, J. C., ... \& Campbell, B. T. (2011). Chromosome substitution lines: concept, development and utilization in the genetic improvement of Upland cotton. Plant breeding, InTech, Slavka Krautzeka, 83, 107-128.

Schumaker, B. C., Stallworth, S., De Castro, E., Fuller, M. G., Shrestha, S., \& Tseng, T. M. (2016). Repeatable Stair-step Assay to Access the Allelopathic Potential of Weedy Rice (Oryza sativa ssp.). MyJoVE Corporation.

Smith, D. T., Baker, R. V., \& Stelle, G. L. (2000). Palmer Amaranth (Amaranthus palmeri) Impacts o Yield, Harvesting, and Ginning in Dryland Cotton (Gossypium hirsutum) Weed Technology, 14(1), 122-126.

Stelly, D. M., Saha, S., Raska, D. A., Jenkins, J. N., McCarty Jr, J. C., \& Gutierrez, O. A. (2005). Registration of 17 upland (Gossypium hirsutum) cotton germplasm lines disomic for different G. barbadense chromosome or arm substitutions.

Sun, B., Kong, C. H., Wang, P., \& Qu, R. (2012). Response and relation of allantoin production in different rice cultivars to competing barnyardgrass. Plant Ecology, 213(12), 1917-1926. 
Székács, A., \& Darvas, B. (2018). Re-registration challenges of glyphosate in the European Union. Frontiers in Environmental Science, 6 , 78.

Tranel, P. J., Wright, T. R., \& Heap, I. M. (2019). The International Survey of Herbicide Resistant Weeds.

VanGessel, M. J. (2001). Glyphosate-resistant horseweed from Delaware. Weed Science, 49(6), 703-705.

Webster, T. M., \& Nichols, R. L. (2012). Changes in the prevalence of weed species in the major agronomic crops of the Southern United States: 1994/1995 to 2008/2009. Weed Science, 60(2), 145-157.

Webster, T. M., \& Sosnoskie, L. M. (2010). Loss of glyphosate efficacy: a changing weed spectrum in Georgia cotton. Weed Science, 58(1), 73-79.

Wilcut, J. W., York, A. C., Jordan, D. L., \& Smith, A. E. (1995). Weed management systems for oil seed crops.

Weiner, J. (2004). Allocation, plasticity and allometry in plants. Perspectives in Plant Ecology, Evolution and Systematics, 6(4), 207215.

Wendel, J. F., Brubaker, C. L. \& Percival, A. E. (1992). Genetic diversity in Gossypium hirsutum and the origin of upland cotton. American Journal of Botany, 79(11), 1291-1310.

Wu, J., McCarty, J. C., Saha, S., Jenkins, J. N., \& Hayes, R. (2009). Genetic changes in plant growth and their associations with chromosomes from Gossypium barbadense L. in G. hirsutum L. Genetica, 137(1), 57-66.

Wu, Z., Soliman, K. M., Bolton, J. J., Saha, S., \& Jenkins, J. N. (2008). Identification of differentially expressed genes associated with cotton fiber development in a chromosomal substitution line (CS-CS-B22sh). Functional \& integrative genomics, 8(2), 165-174.

Xu, J., Smith, S., Smith, G., Wang, W., \& Li, Y. (2019). Glyphosate contamination in grains and foods: An overview. Food Control, 106, 106710.

Zimdahl, R. L. (2018). Fundamentals of weed science. Academic press. 
Table 1. Palmer amaranth (PA) height and chlorophyll reduction values in the presence of cotton chromosome substitution (CS) lines.

\begin{tabular}{|c|c|c|c|c|c|}
\hline $\begin{array}{c}\text { Cotton } \\
\text { Accession }\end{array}$ & $\begin{array}{c}\text { PA Mean } \\
\text { Height } \\
\text { Reduction } 7 \\
\text { DAE (\%) }\end{array}$ & $\begin{array}{c}\text { PA Mean } \\
\text { Height } \\
\text { Reduction } 14 \\
\text { DAE (\%) }\end{array}$ & $\begin{array}{c}\text { PA Mean } \\
\text { Height } \\
\text { Reduction } 21 \\
\text { DAE }(\%)\end{array}$ & $\begin{array}{c}\text { PA Mean } \\
\text { Chlorophyll } \\
\text { Reduction (\%) }\end{array}$ & $\begin{array}{c}\text { Mean } \\
\text { Susceptibility } \\
(\%)\end{array}$ \\
\hline CS-B22sh & 55.23 & 88.11 & 76.82 a & 20.07 & 60.06 \\
\hline CS-B16-15 & 20.82 & 46.23 & $33.34 \mathrm{c}$ & 9.81 & 27.55 \\
\hline CS-T11sh & 23.17 & 42.17 & $38.60 \mathrm{c}$ & 17.00 & 30.24 \\
\hline CS-T26lo & 21.93 & 71.52 & $68.32 \mathrm{ab}$ & 16.42 & 44.55 \\
\hline CS-B17-11 & 27.73 & 35.71 & $40.42 \mathrm{bc}$ & 10.17 & 28.51 \\
\hline CS-M11sh & 30.10 & 44.42 & $37.15 \mathrm{c}$ & 10.46 & 30.53 \\
\hline CS-B10 & 29.65 & 38.11 & $36.92 \mathrm{c}$ & 16.49 & 30.30 \\
\hline UA48 & 10.68 & 27.71 & $28.24 \mathrm{c}$ & 16.50 & 20.78 \\
\hline TM1 & 21.66 & 44.96 & $30.58 \mathrm{c}$ & 11.85 & 27.26 \\
\hline Enlist ${ }^{\circledR}$ & 19.18 & 44.60 & $53.20 \mathrm{abc}$ & 26.49 & 35.87 \\
\hline CS-T17 & 30.23 & 39.70 & $36.77 \mathrm{c}$ & 12.85 & 29.89 \\
\hline CS-T05sh & 22.94 & 32.92 & $24.06 \mathrm{c}$ & 9.78 & 22.43 \\
\hline CS-B26lo & 24.65 & 35.27 & $28.24 \mathrm{c}$ & 8.98 & 24.29 \\
\hline CS-B221o & 20.13 & 41.72 & $33.42 \mathrm{c}$ & 21.18 & 29.11 \\
\hline CS-B12 & 12.17 & 41.50 & $24.70 \mathrm{c}$ & 19.66 & 24.51 \\
\hline
\end{tabular}

${ }^{1}$ Mean height reduction (7, 14, and 21 DAE) and chlorophyll concentration reduction (21 DAE) of recipient Palmer amaranth species in the stair-step structure. The means are separated using Fisher's Protected LSD $(\alpha=0.05)$ with significant and linked groups marked in the table with corresponding letters. The mean susceptibility is derived from the height reduction, and chlorophyll concentration reduction of Palmer amaranth for each CS line tested. 
Table 2. Mean cotton height and chlorophyll reduction values in the presence of Palmer amaranth.

\begin{tabular}{|c|c|c|c|c|c|}
\hline $\begin{array}{c}\text { Cotton } \\
\text { Accession }\end{array}$ & $\begin{array}{l}\text { Cotton Height } \\
\text { Reduction } 7 \\
\text { DAE }(\%)\end{array}$ & $\begin{array}{l}\text { Cotton Height } \\
\text { Reduction } 14 \\
\text { DAE }(\%)\end{array}$ & $\begin{array}{c}\text { Cotton Height } \\
\text { Reduction } 21 \\
\text { DAE }(\%)\end{array}$ & $\begin{array}{c}\text { Cotton } \\
\text { Chlorophyll } \\
\text { Reduction (\%) }\end{array}$ & $\begin{array}{c}\text { Mean } \\
\text { Susceptibility } \\
(\%) \\
\end{array}$ \\
\hline CS-B22sh & 4.99 & $14.41 \mathrm{abc}$ & $2.56 \mathrm{c}$ & 0.47 & 5.61 \\
\hline CS-B16-15 & 18.19 & $6.54 \mathrm{c}$ & $9.28 \mathrm{bcd}$ & 3.13 & 9.29 \\
\hline CS-T11sh & 10.97 & $5.43 \mathrm{c}$ & $3.58 \mathrm{~cd}$ & 2.87 & 5.71 \\
\hline CS-T26lo & 10.50 & $26.93 \mathrm{ab}$ & $9.13 \mathrm{bcd}$ & 15.02 & 15.40 \\
\hline CS-B17-11 & 26.29 & $3.18 \mathrm{c}$ & $2.53 \mathrm{~d}$ & 3.50 & 8.88 \\
\hline CS-M11sh & 16.91 & $10.16 \mathrm{c}$ & $6.59 \mathrm{bcd}$ & 5.92 & 9.90 \\
\hline CS-B10 & 21.57 & $14.10 \mathrm{bc}$ & $6.55 \mathrm{bcd}$ & 2.86 & 11.27 \\
\hline UA48 & 5.16 & $12.25 \mathrm{bc}$ & $7.65 \mathrm{bcd}$ & 0.41 & 6.37 \\
\hline TM1 & 3.25 & $12.25 \mathrm{bc}$ & $3.41 \mathrm{~cd}$ & 4.93 & 5.96 \\
\hline Enlist ${ }^{\circledR}$ & 16.67 & $4.66 \mathrm{c}$ & $21.61 \mathrm{ab}$ & 5.27 & 12.05 \\
\hline CS-T17 & 12.61 & $4.09 \mathrm{c}$ & $3.94 \mathrm{~cd}$ & 4.76 & 6.35 \\
\hline CS-T05sh & 4.65 & $5.84 \mathrm{c}$ & $5.49 \mathrm{~cd}$ & 3.33 & 4.83 \\
\hline CS-B26lo & 11.70 & $9.79 \mathrm{c}$ & $16.51 \mathrm{abc}$ & 2.40 & 10.10 \\
\hline CS-B221o & 16.40 & $31.96 \mathrm{a}$ & $31.33 \mathrm{a}$ & 4.07 & 20.94 \\
\hline CS-B12 & 16.50 & $5.58 \mathrm{c}$ & $9.08 \mathrm{bcd}$ & 4.88 & 9.01 \\
\hline
\end{tabular}

1 Mean height reduction (7, 14, and 21 DAE) and chlorophyll concentration reduction (21 DAE) of donor species Gossypium hirsutum in the stair-step structure. The means are separated using Fisher's Protected LSD ( $\alpha=0.05)$ with significant and linked groups marked in the table with corresponding letters when appropriate. The mean susceptibility is derived from the height reduction and chlorophyll concentration reduction for each cotton line tested. 


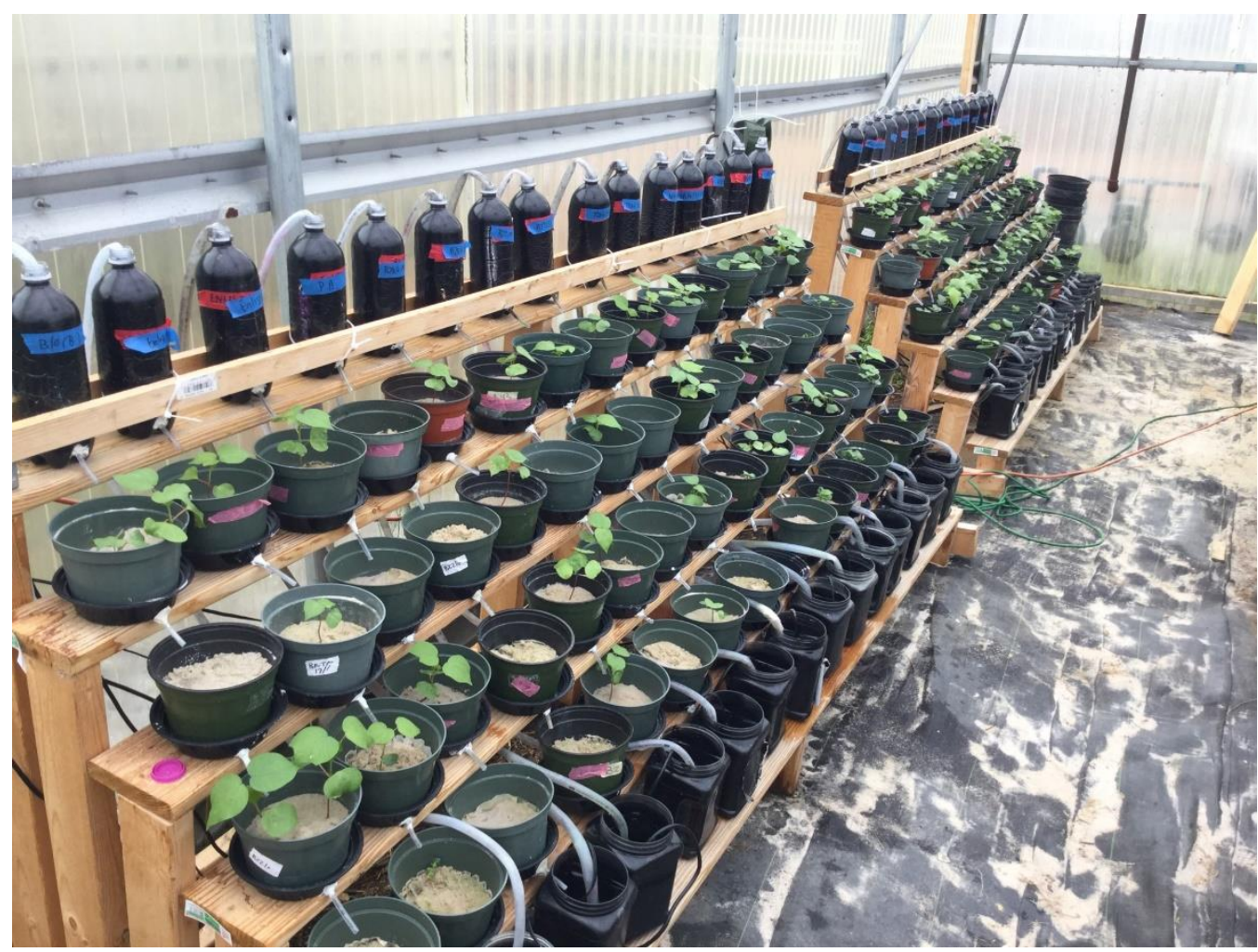

Figure 1. A photograph of the stair-step structure utilized in this experiment for screening allelopathy in cotton. 


\section{Treatment}
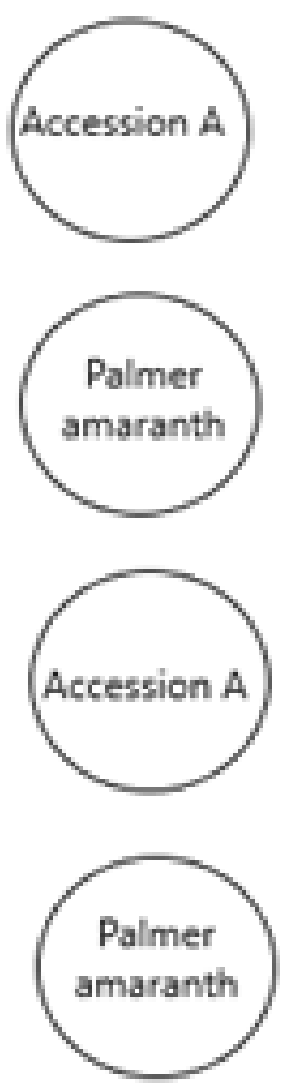
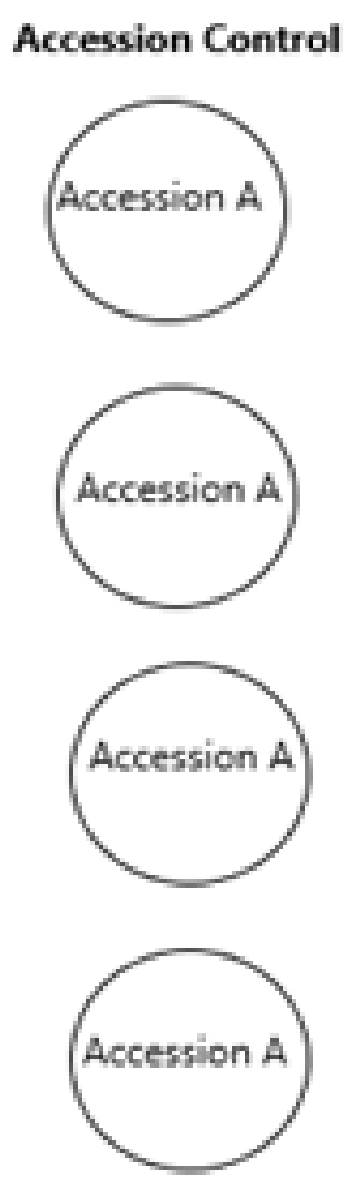

\section{Palmer amaranth} control
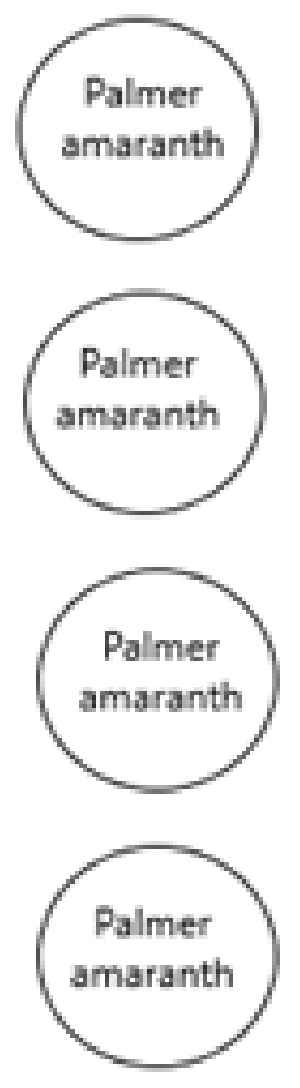

Figure 2. Diagrammatic representation of the stair-step setup. There are two columns for every CS line tested: the treatment column and the control column. The treatment column comprises four pots, two containing the same CS lines and two containing Palmer amaranth (PA). The treatment column starts with a pot of CS cotton, followed by a pot of PA, a pot of the same CS line, and a pot of PA. The control column is composed of four descending pots of the same CS line. This design was repeated for every CS line tested. 


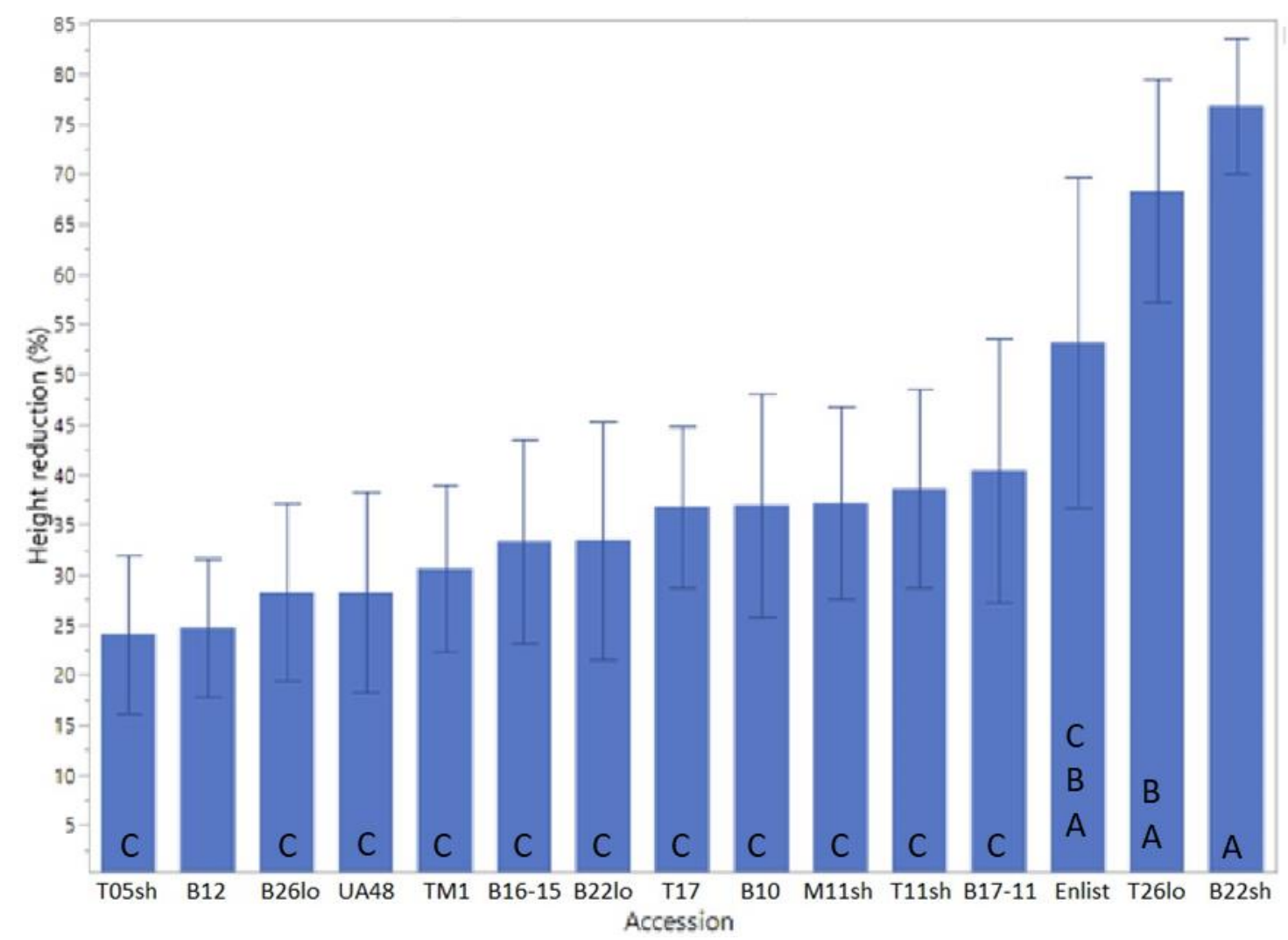

Figure 3. Palmer amaranth height reduction by cotton chromosome substitution (CS) lines at 21 days after establishment (DAE). Data were analyzed using JMP software, where $\mathrm{p}$ was calculated to be 0.0336 . Comparison of means by a student's t-test indicated that CS-B22SH performed better than control lines UA48 and TM1. 


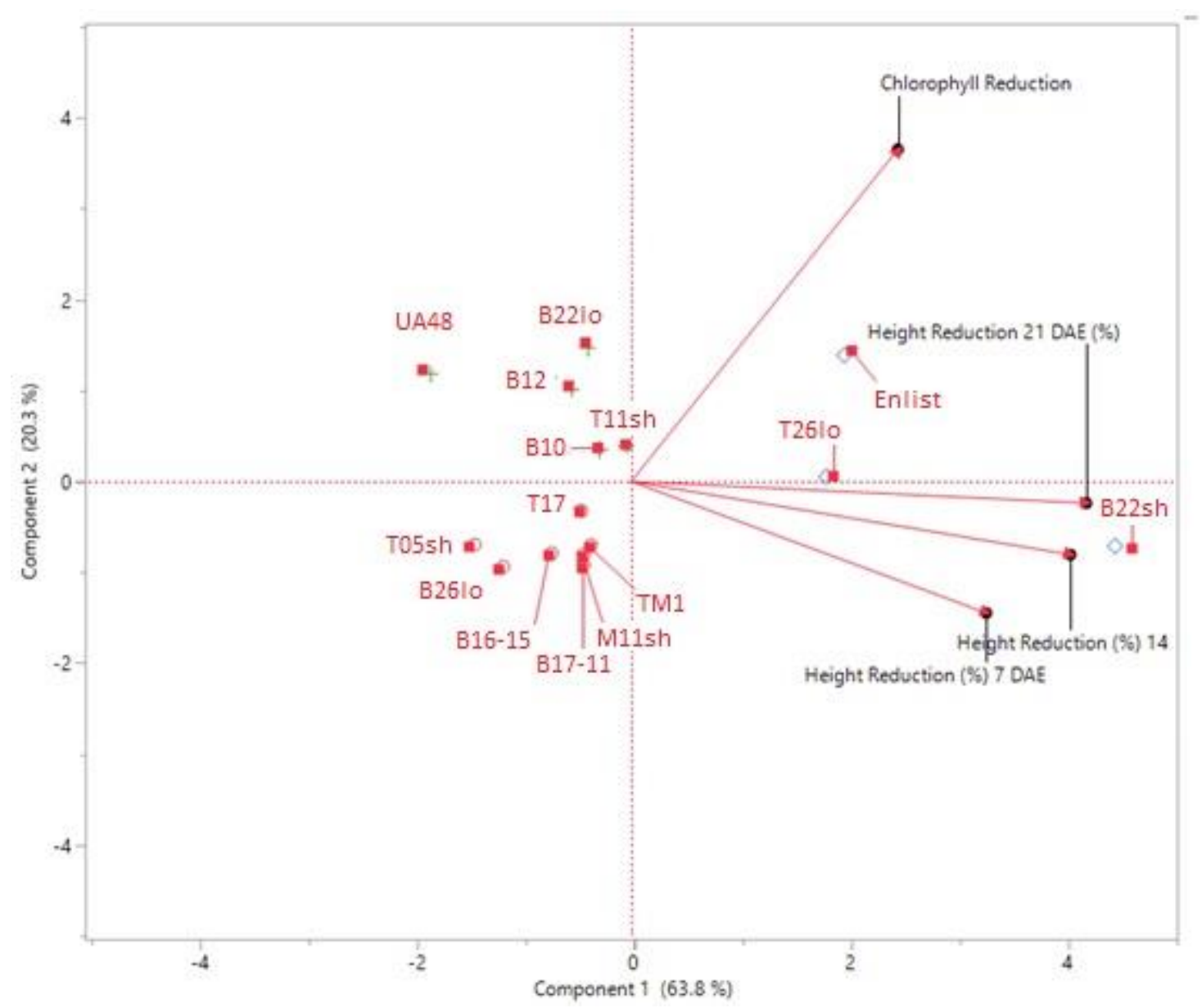

Figure 4. Principal Component Analysis (PCA) with five components: (1) Palmer amaranth mean height reduction 7 days after establishment (DAE) (\%), (2) Palmer amaranth mean height reduction 14 DAE (\%), (3) Palmer amaranth mean height reduction 21 DAE (\%), (4) Palmer amaranth mean chlorophyll reduction 21 DAE (\%), (5) mean susceptibility (\%). Three groups were formed, guided by K-clustering analysis. The first group is composed of lines: CS-B22lo, CS-B12, CS-B10, CS-T11sh, and UA48. This group maintained median Palmer amaranth chlorophyll reduction values. The second group was composed of CS-T05sh, CS-B26lo, CS-B16-15, CS-B17-11, CS-M11sh, CS-T17, and TM1. This group did not have high reduction values for Palmer amaranth chlorophyll concentration or height reduction of any days of data collection. The third group was composed of CS-T26lo, CS-B22sh, and Enlist ${ }^{\circledR}$. This group maintained high Palmer amaranth height reduction values. 